\title{
Антимонопольное право Европейского Союза
}

Хлестов О.Н.*

В настоящее время общепризнано негативное влияние монополистической деятельности на экономику государств. Развитие экономики обеспечивается среди прочего подцержанием конкуренции и борьбой с монополизмом. Как показывает практика, решением таких задач обычно занимаются соответствуюшие государственные органы на основе национального законодательства. Изучение опыта такой деятель ности, в частности правовых средств борьбы с монополизмом, имеет важное значение для всех государств, в том числе и для России, чье законодательство и правоприменительная практика в этой области имеют недостатки. Очередным подтверждением слабости нашего антимонопольного законодательства явился всплеск цен на бензин и соль в последнее время. Особый интерес в этой связи представляет опьт Европейского Союза, в котором действует разветвленная система мер борьбы против монополизма, включающая правовые нормы и механизмы, обеспечивающие соблюдение этих норм. Отрыв ЕС в этой области важен для России также потому, что Россия подцерживает тесные экономические связи с ЕС; ее торговый оборот с Союзом составляет $40 \%$ от всей внешнеэкономической деятельности РФ.

Бурное развитие экономических отношений между членами мирового сообщества в последние десятилетия, возросшая роль транснациональных корпораций на мировой арене потребовали разработки мер по борьбе с монополизмом и в международном масштабе с помощью международного права и международных механизмов. Разработка норм, направленных на ограничение доминирования и монополизации экономики, началась во второй половине XX века в рамках ряда международных организаций, таких как Всемирная торговая организация, на Конференции по торговле и развитию и на других международных форумах. Сегодня, когда идет процесс глобализации, а экономика государств становится все более взаимосвязанной и открытой,

"Хлестов Олег Николаевич - аспирант кафедры международного права Дипломатической Академии МИД России. 
возрастает необходимость в дальнейшем развитии и совершенствовании международно-правовых норм, которые создают правовую базу для борьбы с монополизмом. Опыт Европейского Союза в этой области может быть полезным, поскольку ЕС достиг значительных успехов в создании антимонопольного права, что объясняется рядом объективных факторов. Среди них можно назвать следующие.

1. Интеграция государств - членов ЕС привела к созданию тесных экономических отношений, слиянию экономик государств - членов Союза. Примером является создание единого рынка труда, единой финансовой системы, свободное перемещение людей, товаров и финансовых ресурсов через границы стран, входящих в ЕС. В результате этого, а также учитывая характер правовых норм ЕС, хозяйствующие субъъекты членов Союза имеют право и возможность осуществлять свою деятельность на территории всех государств-членов. Проведение политики монополизации какими-либо транснациональыми корпорациями в одном государстве Союза автоматически затрагивает экономические интересы других членов. Поэтому монополизм наносит ущерб экономике не только одного государства, но всего ЕС в целом, всех входящих в него государств.

2. Если в отдельном государстве можно вести борьбу против монополий на основе его национального антимонопольного законодательства, то в рамках ЕС вести эффективную борьбу с монополизмом, основываясь только на законодательстве отдельных государств - членов Союза, невозможно. Необходимы общие нормы, и это требует проведения единой антимонопольной политики, создания международно-правовых норм, принятия соответствующих стандартов и правил, которые действовали бы во всех странах $\mathrm{EC}$, а также международных механизмов для обеспечения соблюдения этих норм в рамках всего ЕС.

3. ЕС - международная организация, направленная на интеграцию ее членов. На территории членов ЕС действует право Союза и национальные правовые системы входящих в него государств, причем право ЕС имеет приоритет над националыными нормами. Поэтому разработка в рамках ЕС единых международно-правовых норм и стандартов позволяет проводить единую политику регулирования экономики, в которой учитываются интересы не только отдельных государствчленов, но и всего ЕС, создать единую правовую базу для антимонопольного регулирования во всех странах Союза. 
4. Создание единого антимонопольного права Европейского Союза ведет к усилению взаимодействия государств - его членов, их компетентных органов, а также националыных судов, что, в свою очередь, способствует интеграции государств, входящцх в Союз.

\section{Создание антимонопольного права ЕС и его характер}

Первые международно-правовые нормы антимонопольного права ЕС появились в 1957 г. В Договор об учреждении Европейского Экономического Сообщества, заключенный 25 марта 1957 г. шестью государствами - Францией, Германией, Италией, Нидерлањдами, Бельгией и Люксембургом, - (далее - Договор) были включены положения, определяющие основы антимонопольной политики ЕС, основные принципы его антимонопольного права (ст. 85-87²).

Дальнейшее развитие антимонопольного права ЕС осуществлялось путем принятия решений органами Союза, практикой осуществления норм антимонопольного права как органами Союза, так инационалыными органами государств - членов ЕС. Важную роль в этом процессе играла судебная практика, которая дополняла и уточняла основные принципы и нормы антимонопольного права. Она способствовала также постепенному реформированию и совершенствованию антимонопольных механизмов ЕС. Если суммировать основные положения антимонопольного права ЕС, то они могут быть сведены к следующему:

- запрещение хозяйствующим субъектам заключать соглашения и осуществлять иные согласованные действия, которые вели бы к ограничению конкуренции, злоупотреблению ими доминирующим положением на рынках ЕС, к монополизации, что наносит ущерб торговле между государствами-членами ЕС и другим их экономическим интересам. При этом под «хозяйствуюшим субъектом» понимается «любое лицо, занимающееся экономической деятельностью, вне зависимости от его юридического статуса и способов финансирования» ${ }^{2}$. То есть охватывает как государственные органы и корпорации, осуществляющие экономическую деятельность, так и частные компании вне

${ }^{1}$ Глава 1 «Правила конкуренции» раздела 6 «Общие положения о конкуренции, налогообложении и сболижении законов» Договора. В результате дополнений и изменений, внесенных в Договор, статьи 85-87 в новой редакции являются статьями 81-83 Договора.

${ }^{2}$ Hofner (Klaus) and Elsner (Fritz) v. Macrotron GmbH, [1991] ECR I-1979; Commission v. Italy, [1998] ECR I-3851; Fédération Française des Sociétés d'Assurance and others v. Ministère de l'Agriculture et de la Pêche, [1995] ECR I-4013 
зависимости от их организационно-правовой формы, а также группы компаний и физические лица;

- применение различных санкций в отношении нарушителей указанных правил, включая признание ничтожными соглашений и иных согласованных действий хозяйствуюших субъектов. Если действия этих субъектов направлены на монополизацию рынка и искусственное снижение производства или завышение цен, органы ЕС имеют право вводить различные формы экономического регулирования деятельности хозяйствующих субъектов. Антимонопольное право ЕС содержит как нормы материального права, т.е. «относящиеся к вопросам существа (...) отношений» ${ }^{3}$, так и процедурные (или процессуальные) нормы, регулирующие «порядок осуществления официальньх контактов между субъектами международного права с целью решения возникающих между ними проблем ${ }^{4}$. К материальным ${ }^{5}$ относятся, например, нормы, определягщие компетенцию органов ЕС и национальных органов в противодействии монополизму, или нормы, определяющие, являются ли те или иные действия монополистическими, наносящими ущерб экономическим интересам членов Союза. Процедурные, или процессуальные, нормы ${ }^{6}$ регламентируют порядок подачи и рассмотрения органами ЕС уведомлений и ходатайств, порядок и процедуру обжалования принятых решений, процессуальные права и обязанности сторон при рассмотрении споров;

- создание в рамках ЕС разветвленной системы органов, которые наделены исключительно широкими правами. Это органы самого Союза, а также национальные органы. В их задачи входит не только контроль за соблюдением норм антимонопольного права, но и дальнейшее его развитие. Функции и права этих органов можно в какой-то степени сравнивать с функциями и правами, которыми обладают органы исполнительной власти в государствах;

- создание судебных учреждений, в которые можно обжаловать решения органов ЕС, выполняющих указанные выше функции. Это

\footnotetext{
${ }^{3}$ Международное право / Подред. А.А. Ковалева, С.В. Черниченко, 2006. С. 60. ${ }^{4}$ Там же.

${ }^{5}$ Например, Договор об учреждении Европейского Экономического Сообщества, Регламент Совета (ЕС) № 139/2004 о контроле над концентрацией предприятий ${ }^{6}$ Например, Регламент Совета (ЕС) № 1/2003 от 16 декабря 2002 г. о применении правил конкуренции, предусмотренных статьями 81 и 82 Договора о ЕつС, Разъяснение Комиссии о сотрудничестве между национальными судами и Комиссией по применению статей 81 и 82 Договора, ОЈ 1993 С $39 / 6$
} 
судебные учреждения самого Союза (Суд Первой Инстанции, Суд Европейских Сообществ), а также национальные суды.

В результате этого в рамках ЕС создана стройная система, позволяющая эффективно и сбалансированно осуществлять нормы антимонопольного права.

В свете изложенного антимонопольное право ЕС можно было бы определить следующим образом: это совокупность правовых принципов и норм, регулирующих в рамках Евросоюза деятельность государств - его членов - по подцержанию конкуренции и противодействию монополизму и защите их экономических интересов, защите интересов Союза в целом, а также регламентирующих деятельность различных органов и судеб́ных учреждений в этой сфере в рамках ЕС.

Антимонополыное право Союза, действуя непосредственно на территории всех его членов, с одной стороны, воздействует на развитие национального права, способствует его совершенствованию, а с другой - ведет к унификации национальных правовых систем членов Союза. В результате этого создана единая международная система антимонопольного права Союза, базирующаяся на общих международно-правовых принципах и нормах для противодействия монополизму, защите экономических интересов Союза и его членов.

В антимонопольном праве ЕС сложился ряд международно-правовых принципов. К ним можно отнести:

- обязанность членов Европейского Союза не допускать монополистическую деятельность, наносящую вред экономике Европейского Союза и входящих в него государств;

- наднациональный характер регулирования деятельности государств - членов Европейского Союза в антимонопольной сфере;

- взаимодополняющую систему органов и судебных учреждений, как национальных, так и Европейского Союза;

- взаимно уравновешивающую систему прав и обязанностей антимонопольных органов и субъектов, осуществляюших хозяйственную деятельность на территории государств - членов ЕС;

- разветвленную систему санкций за нарушение антимонопольного права $\mathrm{EC}^{7}$;

- порядок обжалования решений, принятьх национальными органами и органами ЕС, контролирующими соблюдение норм антимонопольного права ${ }^{8}$.

${ }^{7}$ Регламент Совета (ЕС) № 1/2003 от 16 декабря 2002 г. о применении правил конкуренции, предусмотренных статьями 81 и 82 Договора о ЕЭС. 
Даншые принщипы являготся ключевыми для функционирования всей системы антимонопольного права Союза.

Касаясь вопроса о месте антимонопольного права в системе права ЕС, можно отметить следующее. Как известно, о праве Европейского Союза порой высказываются разные точки зрения, и в частности по вопросу, является ли оно европейским региональным правом или нет 9 . По нашему мнению, антимонопольное право является составной частью права Европейского Союза, интеграционного права группы государств, входящих в Союз, и одной из отраслей общего права ЕС.

Право ЕС часто делят на первичное, созданное договорами об учреждении Евросоюза, и вторичное, образовавшееся в результате решений органов ЕС, которые имели наднациональный характер, а также решения националыньх органов и судебньх учреждений стран - членов Союза. Антимонопольное право ЕС создавалось таким же путем, причем большая часть его норм является нормами вторичного права ${ }^{10}$.

\section{Структура антимонопольных органов ЕС и их деятельность}

Как уже отмечалось выше, важную роль в осуществлении и развитии антимонопольного права ЕС играет система его органов (Совет министров, Европейская комиссия, Суд первой инстанции и Суд Европейских Сообществ, а также другие органы, такие как Европейский парламент, Экономический и социальный совет, Консультативный комитет по ограничению свободы конкуренпии и монополиям, Консультативный комитет по концентрациям), болышинство из которых является вспомогательными органами, и, наконец национальные антимонопольные органы и суды 25 государсгв - членов ЕС.

\footnotetext{
${ }^{8}$ Разъяснение Комиссии о сотрудничестве между Комиссией и судами государствчленов ЕС по применению статей 81 и 82 Договора, ОЈ 2004 C101/54; Регламент Совета (ЕС) № 1/2003 от 16 декабря 2002 г. о применении правил конкуренции, предусмотренных статьями 81 и 82 Договора о ЕつС.

${ }^{9}$ Эти разные мнения излагаются в ряде работ, например: М.М. Бирюков. Европейская интеграция: международно-правовой подход. М., 2004; в работах ряда ученьх, опубликованных в сборнике «Преподавание права Европейского Союза в российских вузах». М., 2001; Топорнин Б.М. Европейское право. М., 1999; Право Европейского Союза / Под ред. С.Ю. Кашкина; Европейское право / Подред. Л.М. Энтина.

${ }^{10} \mathrm{~A}$ Я. Капустин, анализируя право ЕС, отмечает, что правила конкуренции, т.е. нормы антимонопольного права, входили ужев первичноеправо Союза («Общая характеристика концептуальнх основ правовой системы Европейского Союза». Опубликовано в сборнике «Преподавание права Европейского Союза в российских вузах». М., 2001. С. 33.).
} 
Органом, обладающим самыми широкими полномочиями, является Совет министров. Он состоит из представителей государств-членов в ранге министров. Каждое государство председательствует на Совете в течение шести месяцев на основе ротации. Совет министров наделен правом принимать обязательные решения для развития и осуществления антимонопольного права ЕС, определять компетенцию Европейской комиссии Союза (далее - «Комиссия») и судебных органов, а также соотношение между международно-правовыми нормами ЕС и нормами национального права его членов.

С 1962 г. центральным антимонопольным органом Союза была Комиссия. В 2004 г. в связи со вступлением в ЕС 10 новых членов работа Комиссии была децентрализована, в связи с чем ряд ее функций был передан национальыым органам и судам членов Союза. В дальнейшем это привело к созданию Европейской конкурентной сети, в которую вошли Комиссия ЕС и националыные органы, ведущие борьбу против монополизма. С тем, чтобы более четко определить компетенцию всех звеньев этой сети, было издано специальное Совместное постановление Совета министров и Комиссии, регламентирующее эти вопросы.

В настоящее время (начиная с 1 мая 2004 г.) Комиссия состоит из 25 представителей государств-членов - по одному от каждого государства. С момента, когда число государств - членов ЕС превысит 27 (т.е. после намеченного на 2007 г. вступления в ЕС Румынии и Болгарии), Совет министров должен определить максимальное количество членов Комиссии, которые будут сменяться по принципу ротациигосударств.

Функции, выполняемые указанными выше органами ЕС, можно было бы разделить на две категории:

1. Осуществление контроля и иных мер в целях обеспечения выполнения норм антимонопольного права. Органы ЕС наделены широкими правами в этой области. Они могут признать действия хозяйствующих субъектов не имеющими юридической силы, как нарушающими антимонопольное право, налагать на нарушителей штрафы, причем значительные, применять ряд других мер ${ }^{11}$.

\footnotetext{
${ }^{11}$ В качестве примера можно привести несколько решений Комиссии ЕС о наложении штрафов в последние годы. Среди них: компания «Фольксваген АГ»-30,96 млн евро в мае 2001 г. за поддержание розничных цен на рынке Германии; компания «ДаймлерКрайслер» - 72 млн евро в октябре 2001 г. за политику ограничительной дистрибуции; восемь производителей витаминов - 855,2 млн евро в ноябре 2001 г. за картельный сговор; компания «Нинтендо»-149 млн евро в октябре 2002 г. за ограничение параллельной торговли и т.д. Наконец, в 2004 г. было вынесено беспрецедентное решение о наложении штрафа на компанию «Майкрософт» в размере 497,2 млн евро.
} 
2. Второй вид деятельности органов ЕС связан с дальнейшим развитием и совершенствованием антимонопольного права путем принятия документов, содержащих новые нормы ${ }^{12}$.

Помимо принятия регламентов органы ЕС издают документы, разъясняющие их позицию по различным вопросам антимонопольного права. В них содержатся обобщение практики, разъяснение отдельных моментов, по которым антимонопольныс органы ЕС считают необходимым изложить свою позищию, а также толкование, интерпретация отдельных норм антимонопольного права ${ }^{13}$. Особое значение такие документы приобрели после реформы ЕС 2004 г., когда значительный объем полномочий по рассмотрению антимонопольньх дел был передан от Комиссии национальным антимонопольным органам. И это способствовало их более эффективной деятельности, поскольку у них не было достаточного опыта в рассмотрении таких дел.

Рассматривая антимонопольную систему ЕС, необходимо подчеркнуть, что в ней действует система противовесов. Поскольку Комиссия совмещает правоустанавливающие, исполнительные и правоприменительные функции, что может вести к злоупотреблениям, ее деятельность ограничивается с помощью судебных учреждений ЕС. Огромное значение в этой области имеют Суд первой инстанции и Суд Европейского Союза. Суд первой инстанции, функционирующий с 1989 г., имеет право пересматривать решения Комиссии, в том числе и по примененным ею санкциям. Только за период с 2000 по 2002 год он вынес 79 таких судебньх решений ${ }^{14}$. В компетенцию Суда также входит рас-

${ }^{12}$ В качестве примера можно привести Регламент Совета 1 7/62, ОЈ 1962 13/204, первый акт, установивший базовыеправила применения статей 81 и 82 Договора; Регламент 19/65 ОJ 1965 36/533, Регламент 1215/1999; Регламент Совета (ЕС) № 1/2003 от 16 декабря 2002 г. о применении правил конкуренции, а также Регламент Совета (ЕС) № 139/2004 о контроле над концентрацией предприятий о порядке применения органами ЕС и национальными органами норм антимонопольного права Союза и национальных норм.

${ }^{13}$ Например, Договор закрепляет использование «доминирующего положения» на рынке как наносящего ущерб экономическим интересам стран ЕС. Органы Союза выработали определение этого понятия, которое и применяется на практике. Договором запрещено наносить вред торговле между членами ЕС монопольными действиями. Органы Союза дали разьяснение понятия «торговля», указав, что оно охватывает не только обмен товарами или услугами, но и любую международную экономическую деятельность членов Союза.

${ }^{14}$ Например, Volkswagen AG v. Commission [2000] ECR II 2707; Tate \& Lyle plc and others v. Commission [2001] ECR II 2035; Dansk Rorindustri AS v. Commission [2002] ECR II 1681. 
смотрение исков о компенсации убытков, понесенных в результате оспоренных действий или бездействия Комиссии и других антимонополыных органов. Суд Европейских Сообществ, по сути дела, является апелляционной инстанцией по отношению к решениям Суда Первой Инстанции.

Помимо этого в компетенщию Суда Европейских Сообществ входит принятие предварительных судебных решений по запросу национальных судов относительно толкования или действительности норм права ЕС, включая антимонополыное право ${ }^{15}$, что повышает эффективность деятельности этих судов. Любой национальный суд имеет право запросить такое предварительное судебное решение, если находит, что предварительное решение Суда Европейского Союза по вопросам права ЕС ему необходимо для вынесения судебного решения по конкретному вопросу, который он рассматривает.

Наконец, необходимо отметить и роль националыных антимонопольных органов и националынтх судов 25 государств-членов, на которых после проведенной реформы 2004 г. также лежит обязанность применять антимонопольное право ЕС. Это касается как оценки ими действий хозяйствующих субъектов, так и рассмотрения в определенных случаях конкретных антимонопольных дел.

В последнее время в ЕС начала складываться интересная с точки зрения международного права практика экстерриториального расширения полномочий Комиссии - рассмотрение на основании норм антимонопольного права Союза деятельности, осуществляемой иностранными хозяйствующими субъектами за пределами ЕС. Так, в случае, если сделка о слиянии хозяйствующих субъектов, не являющихся резидентами в государствах - членах ЕС, нарушает существующие в нем нормы, Комиссия применяет меры против этих хозяйствуюших субъектов. Показательны в данном отношении дела Boeing/McDonnell Douglas ${ }^{16}$ и Gencor/Lonrho ${ }^{17}$. В деле Boeing/McDonnell Douglas Комиссия применила нормы права ЕС в отношении сделки между двумя американскими компаниями, не имевшими производства на территории ЕС. Аргументируя свою позициг, Комиссия предупредила компании, не входящие в ЕС, о том, что их деятельность может оцениваться в соответствии с антимонопольным правом Союза на основании

\footnotetext{
${ }^{15}$ Статья 234 Договора.

${ }^{16}$ Boeing/McDonnell Douglas, M.877, OJ 1997 L336/16.

${ }^{17}$ Gencor/Lonrho, M.619, OJ 1997 L11/30.
} 
только одного показателя - оборота компаний в мировом масштабе. Иными словами, Комиссия распространила свою юрисдикцию на любые хозяйствующие субъекты, даже если их деятельность не осуществляется в рамках ЕС.

В деле Gencor/Lonrho Комиссия запретила слияние двух южноафриканских компаний, несмотря на то, что их основная экономическая деятельность осуществлялась в ЮАР. Более того, сделка между указанными компаниями была еще до уведомления Комиссии одобрена властями ЮАР. Интересно, что при рассмотрении апелляции, поданной Gencor/Lonrho на действия Комиссии, Суд Первой Инстанции ЕС ее отклонил, заявив, что «экстерриториальное применение норм антимонопольного права Союза было оправдано с точки зрения международного публичного права, когда планируемая сделка может иметь немедленное и предсказуемое заранее влияние на Сообщество» ${ }^{18}$.

Таким образом, можно констатировать, что в Европейском Союзе достигнуты значительные успехи в сфере борьбы с монополиями, создания условий для поощрения конкуренции, что способствует развитию экономики стран, входящих в ЕС, решению социальных проблем. В антимонопольном праве ЕС уже сложились определенные принципы и нормы, создана система органов с целью обеспечения исполнения этих норм, и это право постоянно развивается и совершенствуется, бесспорно представляя интерес для других государств, в том числе и России.

${ }^{18}$ Решениепо делу Gencor/Lonrho, параграф90. 